\title{
Mixing processes and exchanges in the tropical and the subtropical UT/LS
}

\author{
R. James and B. Legras \\ Laboratoire de Météorologie Dynamique, Ecole Normale Supérieure - CNRS - Université Pierre et Curie, Paris, France
}

Received: 10 April 2008 - Published in Atmos. Chem. Phys. Discuss.: 4 June 2008

Revised: 2 October 2008 - Accepted: 15 October 2008 - Published: 7 January 2009

\begin{abstract}
Both in situ measurements and satellite observations indicate evidence of mixing in the upper troposphere (UT) and the lower-stratosphere (LS). In this study, the measurements performed during the Pre-AVE and Costa-Rica AVE campaigns are analysed with diffusive back-trajectories to assess mixing properties in the tropical and the subtropical UT/LS. A description of cross-tropopause pathways and mixing time scales is provided.

In the subtropics, Troposphere-Stratosphere mixing processes are found to differ in the vicinity of the tropopause and at higher altitudes. Below $350 \mathrm{~K}$, a mixing line observed during Pre-AVE is shown to result from fast and local cross-tropopause irreversible exchange, involving two initially distant air masses with distinct chemical compositions. For measurements located above $350 \mathrm{~K}$, mixing of the tropospheric air in the subtropical stratosphere occurs over a period of a month, the origins of the tropospheric source being localised in the tropical UT and the tropical boundary layer.

In the tropics, quantitative reconstructions of $\mathrm{CO}$ and $\mathrm{O}_{3}$ profiles above $360 \mathrm{~K}$ are obtained for one month backtrajectories calculations, pointing out that long term mixing is essential to determine the chemical composition in the tropical ascent. In particular, the existence of two-way meridional irreversible exchanges between 360 and $450 \mathrm{~K}$ is found to export tropical air in the subtropical stratosphere and to entrain old stratospheric air in the tropical ascent. Mean age of air calculated with a Lagrangian model is shown to be in agreement with the $\mathrm{CO}_{2}$ observations.
\end{abstract}

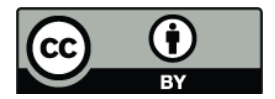

Correspondence to: R. James (james@1md.ens.fr)

\section{Introduction}

One of the most intriguing features of the atmospheric flow is the existence of the tropopause. As defined from WMO, the tropopause is often seen as a roof vertically separating the well mixed troposphere from the stratosphere, where vertical motion is inhibited by the stratification. The tropopause is hence seen as a sharp transition in mixing properties (a mixing barrier) across which tracer profiles are expected to exhibit a jump in the vertical gradient. This is indeed the case for ozone and carbon monoxide profiles, and has led Pan et al. (2004) to define the tropopause as a transition layer centered around the "chemopause", but this view is also consistent with a thin tropopause topped by a mixing layer.

However, a complementary approach emphasizing the role of horizontal transport between the troposphere and the stratosphere can also be proposed. Most of the vertical motion in the extratropics, especially during winter, is along sloping isentropic surfaces that transport and stir air between the boundary layer and the upper troposphere in a matter of a few days or less in case of intense frontogenesis. Dynamical constrains imply that isentropic surfaces cross the tropopause especially in the vicinity of the upper level jet in winter, which is also a permeable transport barriers (Chen, 1995; Haynes and Shuckburgh, 2000b; Haynes et al., 2001). The tropopause is hence seen here as a vertical wall damping horizontal exchanges depending on the season through the strong annual variation in the subtropical jet activity.

The two views concerning the tropopause are reconciled by separating the stratosphere as a reservoir of potential vorticity, mainly maintained as stratification by radiative processes, from the troposphere where stratification and PV are destroyed by boundary layer processes and slantwise convection. 

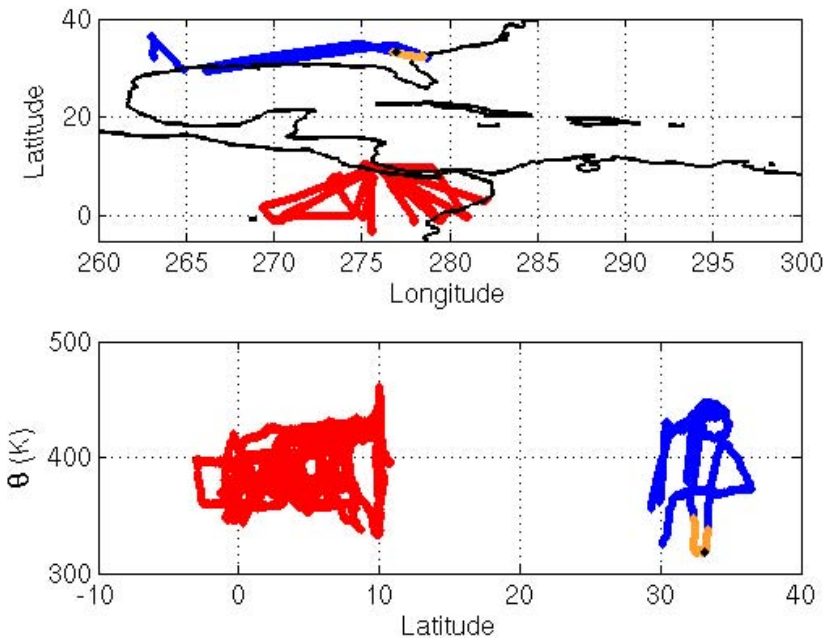

Fig. 1. Aircraft tracks during selected flights of Pre-AVE and CRAVE. Upper panel: horizontal track. Lower panel: meridian track (red: tropical flights, blue: subtropical lower stratosphere, orange: subtropical tropopause layer layer, black: excluded data).

It is now widely admitted, from tracer measurements collected during airborne campaigns (Hoor et al., 2002; Pan et al., 2004) that the transition between the troposphere and the stratosphere in the extratropics is not brutal but occurs over a mixing layer of a couple of kilometers, or $25 \mathrm{~K}$, above the tropopause. Numerous studies have documented the exchanges of air between the lowermost extratropical stratosphere. Actually, it has been shown by Wernli and Bourqui (2002), based on Lagrangian back-trajectories, that the main geographical locations of the exchanges can be retrieved from transport calculations over the time-range of a few days. This short time period is sufficient to assess, at least grossly, the sign and the magnitude of the mean mass exchange: upward beneath the subtropical jet and in the tropics and downward in the extratropics. However, the amount of mass exchanged is still a matter of discussion. Among other constraints, limited resolution makes difficult to distinguish transient, reversible, exchanges from irreversible exchanges (Wernli and Bourqui, 2002). The latter being eventually responsible of the mixing of tropospheric and stratospheric air at the molecular scale.

In the tropics where the average motion is upward at the lapse-rate tropopause, injection of air marked by its tropospheric origin within the stratosphere is not limited to a shallow layer but generates a tape recorder signal deep in the stratosphere (Mote et al., 1996; Neu and Plumb, 1999). However, small-scale and fast fluctuations exhibit less penetration than at the subtropical latitudes (Patmore and Toumi, 2006).

As described by the leaky tropical pipe model in Neu and Plumb (1999), the distribution of tracers in the tropical troposphere is usually considered to result from the combined effect of mean ascending motion, vertical diffusion and limited
Table 1. Table of the Pre-AVE and CR-AVE flights used for subtropical and tropical regions.

\begin{tabular}{cc}
\hline Subtropics & Tropics \\
\hline $19 / 01 / 04$ & \\
& $27 / 01 / 04$ \\
& $29 / 01 / 04$ \\
& $30 / 01 / 04$ \\
$09 / 01 / 06$ & \\
& $19 / 01 / 06$ \\
& $21 / 01 / 06$ \\
& $22 / 01 / 06$ \\
& $25 / 01 / 06$ \\
& $27 / 01 / 06$ \\
& $30 / 01 / 06$ \\
& $02 / 02 / 06$ \\
& $06 / 02 / 06$ \\
& $07 / 02 / 06$ \\
& $09 / 02 / 06$ \\
\hline
\end{tabular}

exchanges with the extratropics (Waugh et al., 1997). There is evidence of more intense meridional exchanges in the lower stratosphere below $450 \mathrm{~K}$ than above (Waugh, 1996; Haynes and Shuckburgh, 2000a) and that a strong seasonal modulation affects both hemispheres. A part of the tropical air newly entered in the stratosphere eventually mixes within the extratropics over a period estimated from one to four months (Volk et al., 1996; Appenzeller et al., 1996; Rosenlof and McCormick, 1997; Andrews et al., 2001; Grewe et al., 2002). However, the vertical extension of this meridional exchange, how far it penetrates above the subtropical jet barrier (Haynes and Shuckburgh, 2000b) and its seasonal variations are still poorly documented from observations and models.

Tracer-tracer relations have often been used to assess mixing properties in the atmosphere (Plumb, 2007). The $\mathrm{CO} / \mathrm{O}_{3}$ relation is particularly useful at the tropopause because $\mathrm{CO}$, which has sources at the surface, reaches mixing ratios of $100 \mathrm{ppbv}$ or more in the troposphere and relaxes to about $12 \mathrm{ppbv}$ within a couple of months in the stratosphere, while $\mathrm{O}_{3}$ is mainly of stratospheric origin and is short lived (a few days) in the troposphere. Hence one expects (Fischer et al., 2000; Hoor et al., 2002; Pan et al., 2004) to see a L-shape distribution in the $\mathrm{CO} / \mathrm{O}_{3}$ for a distribution spanning the upper troposphere and the lowermost stratosphere upon which are superimposed mixing lines due to injection of tropospheric air within the stratosphere.

Although this hypothesis is supported by a number of observations, it has been seldom checked for consistency with atmospheric dynamics. As a quantitative assessment, the advection of passive tracer in the CLaMS model has pointed out that the $\mathrm{CO} / \mathrm{O}_{3}$ relationships in the vicinity of the extratropical tropopause could effectively be explained from TS mixing (Pan et al., 2006). However, previous studies limited the integrations of trajectories to relatively short time-scale 

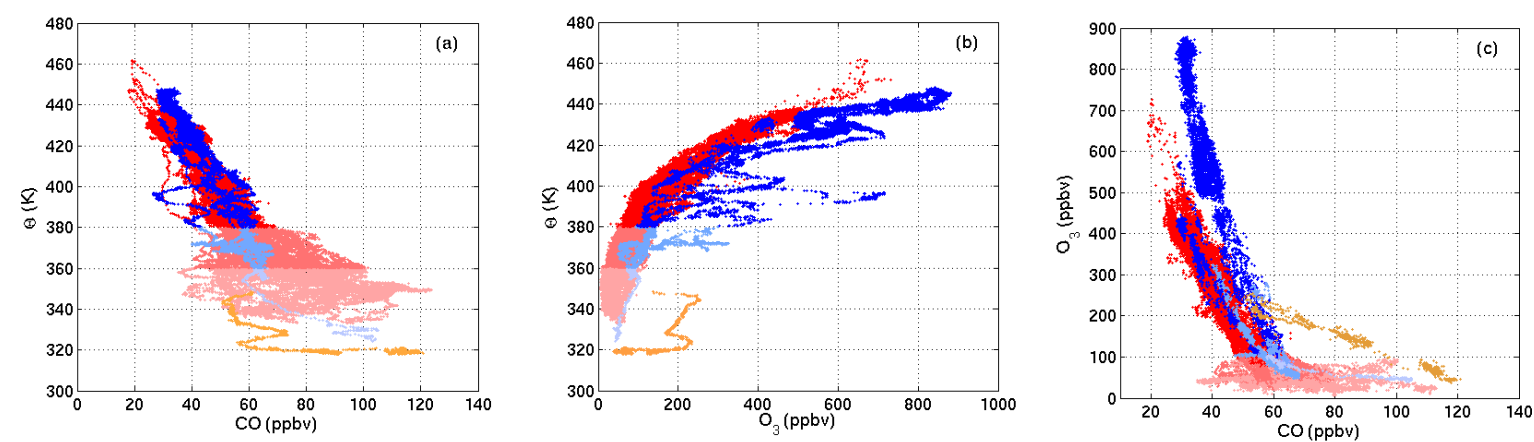

Fig. 2. (a) $\mathrm{CO}$ as a function of potential temperature; (b) $\mathrm{O}_{3}$ as a function of potential temperature; (c) tracer-tracer relation with $\mathrm{O}_{3}$ as a function of $\mathrm{CO}$. Color code indicates the potential temperature (pink to red for tropical data and pale to dark blue for subtropical lowerstratosphere) with discontinuities at $\theta=360 \mathrm{~K}$ and $\theta=380 \mathrm{~K}$, and marks the mixing line (orange). Black points in Fig. 1 are discarded from this figure.

that did not allow one to investigate TS transport and mixing processes in the tropics between $350 \mathrm{~K}$ and $450 \mathrm{~K}$ or above $360 \mathrm{~K}$ at higher latitudes.

This work investigates mixing properties across the tropopause using long Lagrangian integration times up to 35 days and a representation of turbulent dispersion by Feynman-Kac method. The model is applied to the analysis of in situ measurements in the tropical and subtropical UT/LS. Section 2 presents the Pre-AVE and CR-AVE dataset used in this work. Section 3 presents the numerical methods. Section 4 shows the results for the case of a mixing line in the subtropics. Section 5 discusses mixing processes above $350 \mathrm{~K}$ in the subtropics and Sect. 6 discusses mixing timescale in the tropics. Section 7 offers further discussion and conclusions.

\section{In-situ measurements}

\subsection{Campaigns and instruments}

The Pre-AVE and the Costa-Rica AVE campaigns took place respectively in winter 2004 and winter 2006 over the Gulf of Mexico and Costa-Rica (Fig. 1). They are part of five AURA Validation Experiments (AVE) performed by NASA to validate the AURA instrument. With 12 tropical flights on board of the WB-57, the Pre-AVE and the Costa-Rica AVE campaigns provide the largest dataset collected by an instrumented stratospheric plane in the tropics providing an homogeneous dataset for $\mathrm{CO}$ and $\mathrm{O}_{3}$. Spanning the range of altitudes between $350 \mathrm{~K}$ and $450 \mathrm{~K}$ in potential temperature, the flight tracks encompass the lapse-rate tropopause and permit a statistical assessment of the cross-tropopause processes in this region. A number of additional subtropical flights during the same campaigns allows direct comparisons of mixing properties between tropics and extratropics.
Ozone was measured at $1 \mathrm{~Hz}$ frequency by the NOAA Dual-Beam UV-absorption ozone photometer (Proffitt et al., 1989 ) with a relative precision of 5 ppbv (average uncertainty $5 \%$ ). The carbon monoxide has been measured at $0.5 \mathrm{~Hz}$ (with interspersed $8 \mathrm{~s}$ calibration gaps) by the ARGUS DIAL instrument (Loewenstein et al., 2002; Lopez et al., 2006), providing a precision of near $2 \mathrm{ppbv}(3 \%)$. The carbon dioxide has been measured with the non dispersive absorption $\mathrm{CO}_{2}$ analyser, which is calibrated in flight, at $1 \mathrm{~Hz}$ with precision of 50 to $100 \mathrm{ppbv}$ (Daube et al., 2002). Temperature, pressure and position are recorded at $1 \mathrm{~Hz}$, providing an horizontal resolution of near $250 \mathrm{~m}$ and a vertical resolution during ascent and descent of near $10 \mathrm{~m}$.

In order to distinguish the tropical and the extratropical signatures, we have selected two well-separated subsets among the flights of the WB-57 (Table 1). The tropical set contains twelve flights performed equatorward of $10 \mathrm{~N}$. The subtropical set contains two flights performed poleward of $30 \mathrm{~N}$. Flights performed at intermediate latitudes have been discarded from our analysis. The two meteorological situations associated with the selected flights in the subtropical ensemble exhibit properties (tropopause altitude, tropopause folds, ...) which are characteristic of the extratropics. The presence of such dynamical features allows a direct comparison with the SPURT dataset in the extratropics (Hoor et al., 2004), although the subtropical region near $30 \mathrm{~N}$ is also under the influence of the tropical circulation.

\subsection{Tracer-tracer relationship and mixing}

Figure 2 shows the distributions of $\mathrm{CO}$ and $\mathrm{O}_{3}$ as a function of altitude and the $\mathrm{CO} / \mathrm{O}_{3}$ diagram for the two sets of tropical and subtropical flights which are superimposed for comparison. 


\subsubsection{Subtropics}

In the subtropics, a $\mathrm{CO} / \mathrm{O}_{3}$ relationship connecting pure tropospheric values of $\mathrm{CO}(>100 \mathrm{ppbv})$ to stratospheric values of ozone ( $>200 \mathrm{ppbv}$ ) is captured by one of the two subtropical flights. Observed between $\theta=320$ and $350 \mathrm{~K}$, the linearity of the distribution is highly suggestive of a mixing line, and will be referred in the sequel as the subtropical tropopause layer relationship. Such kind of $\mathrm{CO} / \mathrm{O}_{3}$ relationships have been first identified in (Hoor et al., 2002), and then frequently observed in the extratropics. Idealised tracer experiment in the CLaMS model have confirmed that these distributions are the results of cross-tropopause mixing (Pan et al., 2006).

We would like here to emphasize that a irreversible mixing line requires the mixing event to occur between two air masses initially distant in chemical composition. This process differs from the case where a column of air spanning the tropopause, and sampling both tropospheric and stratospheric branches of the $\mathrm{CO} / \mathrm{O}_{3}$ diagram, is mixed. In the first case, the mixing results from the irreversible exchange between two identified sources, the chemical composition of each parcel being determined by the proportion of air issued from one of the sources at the end of the mixing event. All the mixtures lie on the same mixing line, and an unique relationship can be retrieved along any transect across the mixed region. In the second case, mixing is allowed between air parcels with composition distributed in the tracer-tracer plane. Unless this initial distribution is a line, the mixing line is not unique and appears as an artifact of sampling along the flight track. $\mathrm{CO}-\mathrm{O}_{3}$ correlations are most often seen as an irreversible mixing line. We use in Sect. 4 a Lagrangian approach to verify this statement on the $\mathrm{CO}-\mathrm{O}_{3}$ mixing line observed here, and highlight the processes involved in its formation.

In the subtropics and extratropics, two mechanisms can perform mixing between two air masses of distant initial composition and location: the ascent along the warm conveyor belt (Wernli and Bourqui, 2002), which can be very intense near atmospheric fronts, and the detrainment of deep convective clouds above the tropopause (Mullendore et al., 2005). We show in Sect. 4 that the first mechanism is indeed responsible of the observed mixing line.

Due to the limited amount of data, the tropospheric branch of the $\mathrm{CO} / \mathrm{O}_{3}$ relationship reduces to a few points below $360 \mathrm{~K}$ in the subtropics. At higher levels, the stratospheric parcels split apparently in two subsets, the smaller one being superimposed onto the tropical branch while most of them being distributed along another branch with a steeper slope reaching higher $\mathrm{O}_{3}$ values. The existence of a separate branch overlaying the tropical branch is an indication that some of the air in the subtropics has intruded recently from the tropics. This interpretation is supported by (Hoor et al., 2004, 2005) who have suggested that meridional mixing of upper tropospheric tropical air in the lowermost extratropical stratosphere could be responsible of the slope discontinuity in the $\mathrm{CO} / \mathrm{O}_{3}$ relationship that they found at $\Delta \theta=25 \mathrm{~K}$ above the tropopause. Here we find also, that the branching between the subtropical tropopause layer relationship and the main branch of the subtropical stratospheric relationship is located at $350 \mathrm{~K}$, around $25 \mathrm{~K}$ above the tropopause. The fact that the subtropical stratospheric relationship extends below this merging point at $350 \mathrm{~K}$ is an additional indication of in-mixing with tropospheric tropical air over the subtropical tropopause layer.

In the stratosphere, mixing processes are produced by intermittent patches of turbulence combined with horizontal stirring and fluctuations in the heating rate, inducing fluctuations of cross-isentropic motion. Estimations of the large-scale vertical diffusion fall within a range of $0.1-0.5 \mathrm{~m}^{2} \mathrm{~s}^{-1}$ at mid-latitudes, which correspond to much slower mixing processes than in the vicinity of the tropopause. We will show in Sect. 5 how the mixing properties of the subtropical stratosphere can be related to the tropical tropospheric impact in this region.

\subsubsection{Tropics}

In the tropics, it is easy to distinguish a tropospheric branch in the $\mathrm{CO} / \mathrm{O}_{3}$ relationship, with low values of $\mathrm{O}_{3}$ and $\mathrm{CO}$ ranging from $40 \mathrm{ppbv}$ to $120 \mathrm{ppbv}$ below $380 \mathrm{~K}$ and, a stratospheric branch with $\mathrm{O}_{3}$ above 100 ppbv and $\mathrm{CO}$ below $60 \mathrm{ppbv}$ above. The absence of mixing lines in the 12 flights of the Pre-AVE and CR-AVE dataset and the striking compactness of the stratospheric branch emphasize that transport and mixing processes occur over relatively long time-scales.

\section{Methods}

\subsection{Reconstruction}

As argued before, the $\mathrm{CO} / \mathrm{O}_{3}$ relationship suggests that the lower tropical and extratropical stratosphere separate into several layers and mixing regimes according to the time scale and the origin of the tropospheric influence.

In order to determine how tracer distribution is controlled by advection and turbulent diffusion in the vicinity of the tropopause, we investigate how Lagrangian diffusive reconstructions are able to explain the observed tracer relationship.

The deterministic part of the Lagrangian reconstruction method used in this study is based on the reverse integration of trajectories with TRACZILLA, a modified version of FLEXPART (Stohl et al., 2005) which uses winds from the European Centre of Medium range Weather Forecast (ECMWF) projected on a latitude-longitude grid with $0.5^{\circ}$ resolution in the horizontal and on 60 hybrid levels in the vertical (91 in 2006 for CR-AVE), with 3-h temporal resolution obtained by combining analysis available every $6 \mathrm{~h}$ with short time forecasts at intermediate times. Trajectories are initialized along the flight track at $1 \mathrm{~Hz}$ resolution and then integrated backwards over 40 days. We interpolate the 
ECMWF potential vorticity and potential temperature along the trajectory in order to localize our parcel with respect to the tropopause.

In order to take into account that each air parcel is actually a mixture of particles from various origin we split each parcel into 200 particles released from the same point. These particles are submitted to an additional random noise in the vertical that represent the turbulent diffusion $D$ due to smallscale motion missing in the ECMWF winds (Legras et al., 2005). We choose this procedure instead of an arbitrary initial separation because it is consistent with the underlying physics and also because the applied diffusion can be estimated from the comparison of small-scale observed tracer fluctuations and reconstructions (Legras et al., 2005; Pisso and Legras, 2008). As shown below, the value of the diffusion coefficient is chosen in order to fit the observations but the results are found to be weakly sensitive to the precise values of this parameter. Notice that large-scale motion is here explicitly taken into account and that the added diffusion is meant to represent the small-scale processes and differs from the large-scale diffusion mentioned in Sect. 2.2. Notice also that the added diffusion governs dispersion of the cloud of points associated with each parcel only during the first days of the integration, after which dispersion is mainly due to the wind strain.

The reconstructed value of the tracer is obtained by averaging the values of the tracer at the locations reached by the particles at the end of the reverse integration. Potential vorticity is provided by the ECMWF analysis while chemical tracers are provided by the three-dimensional chemistrytransport model REPROBUS (REactive Processes Ruling the Ozone BUdget in the Stratosphere) which uses a comprehensive treatment of gas-phase and heterogeneous chemical processes in the stratosphere (Lefèvre et al., 1994, 1998). In REPROBUS, long-lived species, included ozone, are transported by a semi- Lagrangian scheme forced by the ECMWF wind analysis. The model is integrated on 42 hybrid pressure levels that extend from the ground up to $0.1 \mathrm{hPa}$.

When diffusion $D$ is set to zero or is very small, the origin of each parcel is found to be localized even after several weeks and is very sensitive to the initial location. As a result, the fluctuations of a reconstructed tracer grow indefinitely with time when $D=0$ or saturate to very high values when $D$ is too small. In previous work (Legras et al., 2005), $D$ was adjusted in order to fit the observed fluctuations. Here we need also to take into account the errors of the analyzed wind field used in the reconstruction which are usually larger in the tropics than at mid and high latitudes, in particular regarding the divergent circulation.

Consequently, we retain only the parcels for which the ozone reconstruction provides a value which deviates from the observed value by less than $30 \%$ and we adjust $D$ in order to maximize the percentage of retained parcels. Table 2 shows that this minimum is reached for $D \approx 1 \mathrm{~m}^{2} \mathrm{~s}^{-1}$ in the subtropical tropopause layer, retaining $60 \%$ of the parcels,
Table 2. Percentage of retained parcels for different values of the diffusivity added to the advection scheme.

\begin{tabular}{lccccccc}
\hline & \multicolumn{8}{c}{$D\left(\mathrm{~m}^{2} \mathrm{~s}^{-1}\right)$} \\
\hline & 0.01 & 0.05 & 0.1 & 0.5 & 1. & 2. & 5. \\
Tropics & 60 & 64 & 67 & 44 & 20 & - & - \\
Sub-Tropics & 62 & 79 & 80 & 71 & 33 & - & - \\
Dyn. trop. & - & - & 52 & 57 & 60 & 57 & 52 \\
\hline
\end{tabular}

while it is reached for $D \approx 0.1 \mathrm{~m}^{2} \mathrm{~s}^{-1}$ in the subtropics above $350 \mathrm{~K}$ and in the tropics, retaining respectively $80 \%$ and $65 \%$ of the parcels. The back-trajectories have been integrated over 9 days for the particles initialized in the subtropical tropopause layer and over 1 month for the particles initialized in other regions as explained below. The subtropical tropopause layer value is consistent with the results of Pisso and Legras (2008). The lower value in the subtropical and tropical upper troposphere is similar to that found in the extratropical stratosphere by Legras et al. (2005) and in agreement with the values estimated by Mote et al. (1996) in the tropical ascent.

\subsection{Stratospheric air proportion}

As the cloud of particles merging into a given parcel evolves backward in time, its relative proportion among the stratosphere and the troposphere allows one to determine in which proportion stratospheric and tropospheric air mix within the parcel.

Potential temperature and potential vorticity are interpolated along the backward trajectories in order to determine their location with respect to the tropopause. Particles with a potential vorticity exceeding $4 \times 10^{-6} \mathrm{~K} \mathrm{Kg}^{-1} \mathrm{~m}^{2} \mathrm{~s}^{-1}$ or with a potential temperature above $380 \mathrm{~K}$ are labeled as stratospheric while the other ones are considered as tropospheric.

The Stratospheric Air Proportion(SAP) is then defined for each parcel and for a given reconstruction time as the proportion of backward trajectories among 200 particles which are located in the stratosphere at that time.

\subsection{Age of air}

The mean age of air (Waugh and Hall, 2002) is defined as the mean duration since a parcel entered the stratosphere. This age can be estimated from our calculations by averaging this duration, for each parcel, over the particles which have crossed the reference surface. A generalized age is defined by choosing a reference surface which is not the tropopause, like an isentropic surface within the TTL.

The mean age of air can also be estimated, following Park et al. (2007), using $\mathrm{CO}_{2}$ as an age marker. During JanuaryFebruary, $\mathrm{CO}_{2}$ exhibits a global trend of $28-30$ ppbv per day. Since the accuracy of the Harvard instrument on board the 

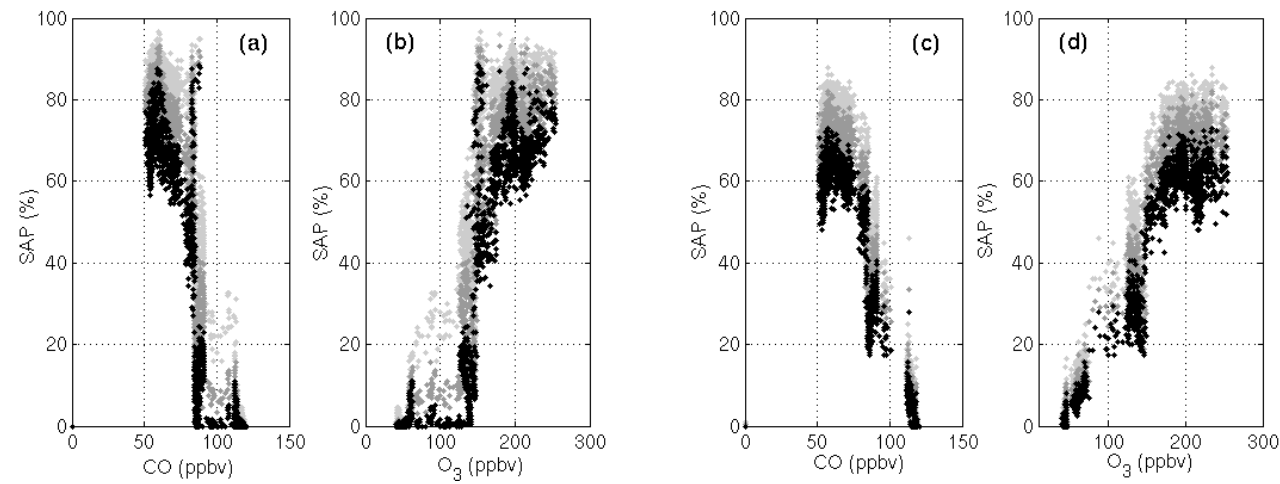

Fig. 3. (a-b) SAP as function of observed $\mathrm{CO}$ and $\mathrm{O}_{3}$ for 2-day backward trajectories and parcels belonging to the subtropical subtropical tropopause layer; (c-d) same as (a-b) for 9-day backward trajectories. Light, medium and dark gray shows SAP for tropopause defined, respectively as, 2,3 and $4 \times 10^{-6} \mathrm{~K} \mathrm{Kg}^{-1} \mathrm{~m}^{2} \mathrm{~s}^{-1}$ surface.

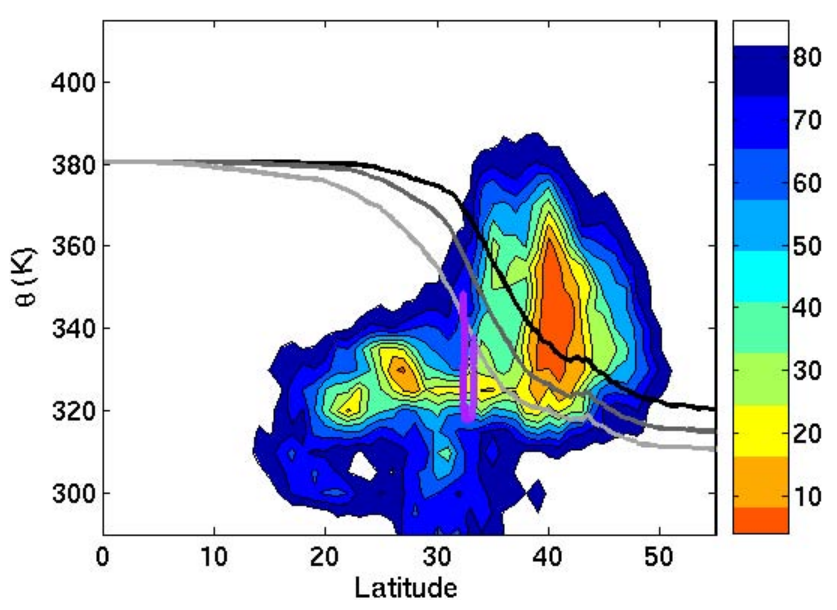

Fig. 4. Meridional distribution of the probability density function (pdf) of the particles contributing to the parcels belonging to the subtropical tropopause layer after a 9-day backward integration and as a function of latitude and potential temperature. The violet line shows the location of flight track along which the parcels have been initialized. The pdf is first calculated by binning parcels within boxes of $1 \mathrm{~K} \times 1 \mathrm{deg}$. Contours show integrated percentage of parcels by aggregating boxes starting from the most populated. The thick line shows the average tropopause calculated as the lower level satisfying either $\theta>380 \mathrm{~K}$ or $P V>2,3$ or $4 \times 10^{-6} \mathrm{~K} \mathrm{Kg}^{-1}$ $\mathrm{m}^{2} \mathrm{~s}^{-1}$ (light, medium and dark gray).

WB-57 is 50-100 ppbv (Daube et al., 2002), the age of air can be estimated with an accuracy of 2-3 days. The calculation is as follows. First, we reduce all the $\mathrm{CO}_{2}$ profiles of the CRAVE campaign to a single date chosen on 19 January 2006 by shifting all data by a linear 30 ppbv per day tendency. This generates the reduced $\mathrm{CO}_{2}$. Then we calculate the age at a given altitude from the difference between the measured $\mathrm{CO}_{2}$ and the average concentration at a reference level chosen as an isentropic surface $(360,370$ or $380 \mathrm{~K})$, converted into an age dividing by the same flat tendency as aforementioned. This procedure is essentially identical to that used in Park et al. (2007).

\section{Mixing time-scale in the subtropical tropopause layer}

In Fig. 3, we compare observed $\mathrm{CO}$ and $\mathrm{O}_{3}$ for the subtropical tropopause layer layer defined in Sect. 2.2 with the SAP calculated from backward trajectories and several definitions of the tropopause. In the left two panels, where the SAP is calculated after an integration of 2 days, there is no visible relation between tracer value and SAP. In the right two panels where back-trajectories are integrated over 9 days, a linear relation emerges for both $\mathrm{CO}$ and $\mathrm{O}_{3}$ mixing ratios.

This result provides a stringent confirmation that the subtropical tropopause relationship is correctly interpreted as a mixing line between a tropospheric source and a stratospheric source. Indeed, if chemistry was driving $\mathrm{CO}$ and $\mathrm{O}_{3}$ over the considered time-scale, there would be no reason to obtain a relation with a quantity that depends purely on transport and mixing. Note that, this result does not depend on the precise PV value chosen to define the tropopause, as shown by the different grey ensembles in Fig.3.

However, the linear relation between SAP and the tracers is only obtained after a minimum integration time which is required for the cloud of particles merging into a single parcel to sample the stratospheric and tropospheric origins. This time can be seen as a mixing time required to mix stratospheric and tropospheric air into the parcel. It does not contain any scale dependence on resolution, unlike the convergence time of the reconstructions in Legras et al. (2005) and is associated, as we shall see shortly, to a fast meso-scale event. 


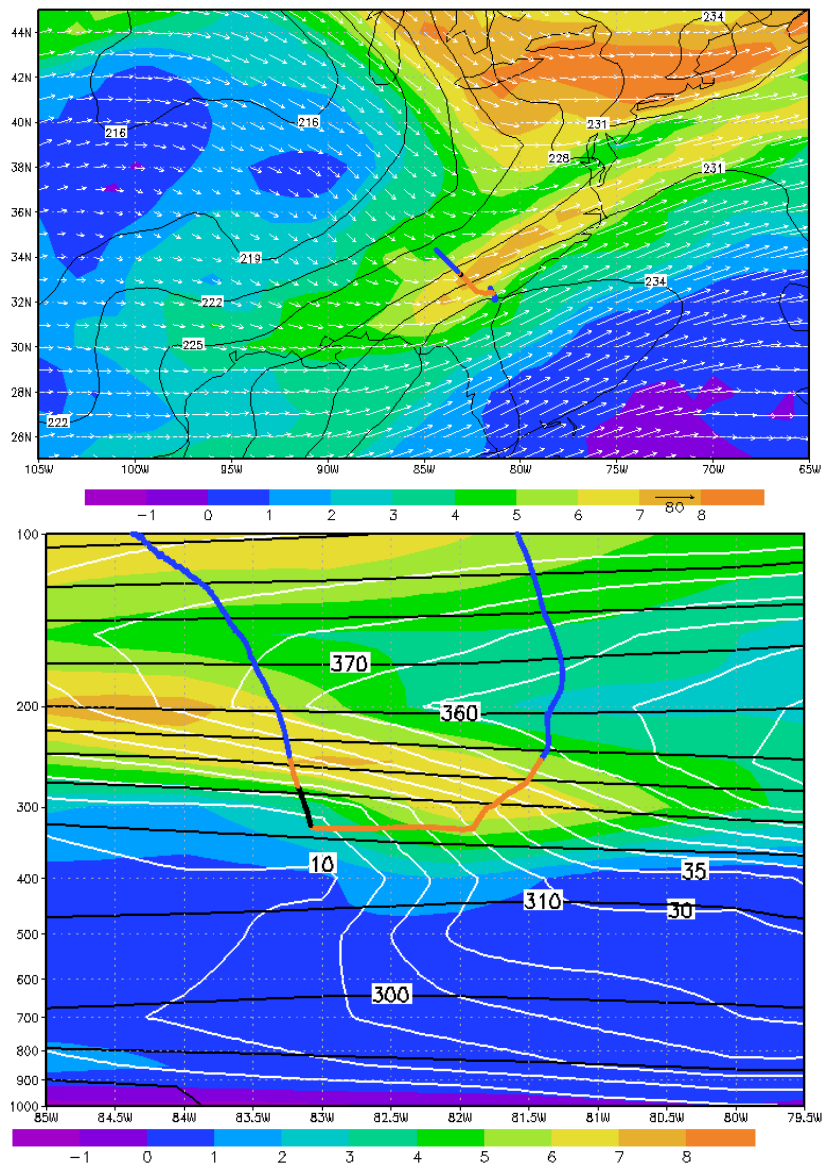

Fig. 5. Upper panel: meteorological conditions at $250 \mathrm{hPa}$ on 19 January 2004 at 18:00 UT from ECMWF operational analysis. Colors show PV, contours represent temperature and arrows show wind. Lower panel: section in the vertical plane of the flight track. Colors show PV, black contours represent potential temperature and white contours show intensity of transverse wind. In both panels, the flight track is projected as a thick line with the same color codes as in Fig. 1.

In order to investigate further the tropospheric and stratospheric sources, Fig. 4 shows the probability density function (pdf) of the locations after a 9-day backward integration of particles that contribute to the subtropical tropopause layer. The distribution exhibits a striking bimodality with two clusters that separate both in altitude and latitude, one being located within the troposphere, near $25 \mathrm{~N}$ and $330 \mathrm{~K}$, equatorward to the jet, and the other one in the extratropical stratosphere, near $40 \mathrm{~N}$ with a distribution of potential temperature from $320 \mathrm{~K}$ to $360 \mathrm{~K}$ that matches that of the mixing line in Fig. 2.

Interestingly, the sources are separated by a distance of $1500 \mathrm{~km}$, which is on the order of a Rossby radius at those latitudes. The existence of a link between the two clusters in Fig. 4 around the isentrope $325 \mathrm{~K}$ and the fairly
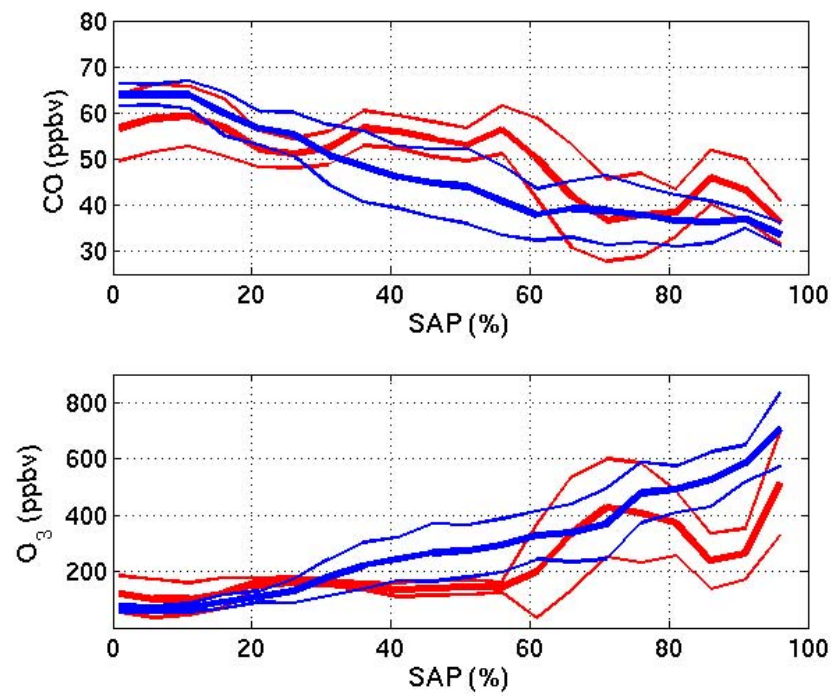

Fig. 6. in situ measurements of $\mathrm{CO}$ (top) and $\mathrm{O}_{3}$ (bottom) as a function of SAP calculated after 9 days (red) and 35 days (blue). Thick lines show the average mixing ratio, and thin lines show one standard deviation for each SAP value.

small latitudinal extend of the origins of stratospheric parcel suggest that the transport that brought the tropospheric and stratospheric parcels together has been first accomplished by quasi-isentropic motion followed by irreversible mixing. As a matter of fact, the flight track crossed a region of wind shear on the north side of a jet streak as shown in the upper panel of Fig. 5. Such situations are often associated with upper level fronts. Indeed, the vertical cross-section along a direction approximating the flight track, shown in the lower panel of Fig. 5, exhibits the typical pattern of a folded tropopause, embedding the portion of the flight track associated with the mixing line, within the layer $320-350 \mathrm{~K}$. The relatively flat shape of the isentropic surfaces with respect to the slope of the PV distribution within the front (realized mostly as shear) is an indication that the flight occurred during the decay of the front, after flattening of the isentrope by the crossfrontal circulation and shear induced mixing beneath the jet. This scenario has been checked to be consistent with the upstream evolution of the front over the previous four days (not shown). As the time scale of the front is about one week, this is also consistent with the duration required to establish the link between SAP and the mixing line as discuss above. This is in agreement with previous results on tropospherestratosphere exchanges beneath the subtropical jet (Shapiro, 1980; Chen, 1995).

\section{TS mixing above the subtropical tropopause layer}

In this section, we investigate the TS mixing above the subtropical tropopause in a range of $\theta$ values larger than $350 \mathrm{~K}$. 


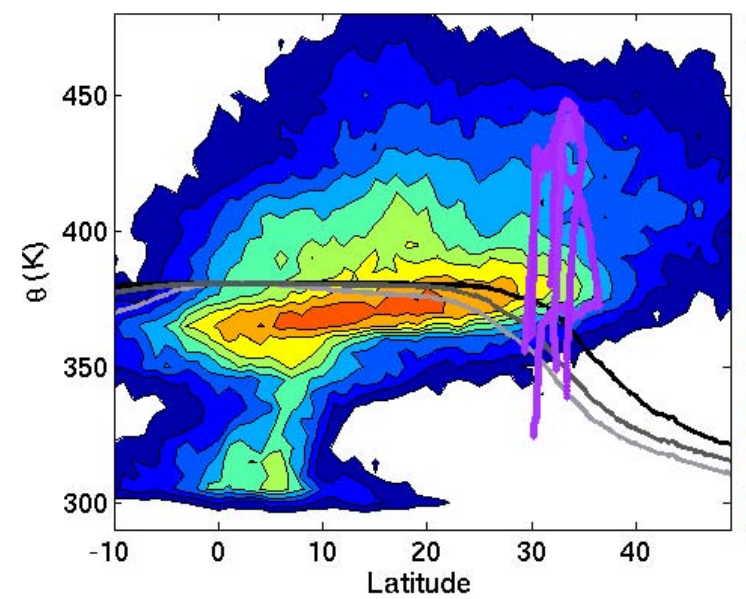

Fig. 7. Same as Fig. 4 for the distribution of subtropical particles initialized above $350 \mathrm{~K}$ after an integration of 35 days.

We expect mixing times larger than those associated with mid-latitude synoptic perturbations due to the limited impact of the tropospheric intrusions at this altitude. Figure 6 compares the mixing ratios of $\mathrm{CO}$ and $\mathrm{O}_{3}$ as a function of the SAP after 9 and 35 days. After 9 days, both species exhibit almost constant compositions for SAP lower than $50 \%$ whereas, for large SAP, the mean mixing ratio is not an invertible function of SAP and the dispersion for a given SAP is large.

The non existence of a clear relation between SAP and tracer mixing ratios indicates that, over 9 days, the particles have not yet been sorted into well defined tropospheric and stratospheric ensembles. We infer from this result that although some tropospheric air may have been stirred with stratospheric air over the range of one week by reversible exchanges, this duration is insufficient to perform mixing down to the molecular scale and impacts on the air composition. In contrast, for trajectories integrated over a period of one month, compact quasi-linear relations are retrieved between SAP and tracers for the whole range of tracer values. This bijective relation allows a quantitative estimate of the mixing ratio of each measured species from the proportion of the air parcel which was in the troposphere one month before. In agreement with in situ measurements studies from the SPURT dataset (Hoor et al., 2004, 2005), this result indicates that the chemical composition of the subtropical parcels above $350 \mathrm{~K}$ results from long-term mixing processes across the tropopause. This cannot be confused with an effect of neglected chemistry since the same relationship is observed for $\mathrm{CO}$ and $\mathrm{O}_{3}$.

Figure 7 shows the distribution of the subtropical particles after an integration of 35 days. Here, it is clear that the main source is found in the TTL northward of the equator. Below $360 \mathrm{~K}$, the sharp vertical gradient north to $15 \mathrm{~N}$ indicates that meridional exchanges are inhibited at the altitude of the jet core in agreement with the current understanding of the bar-
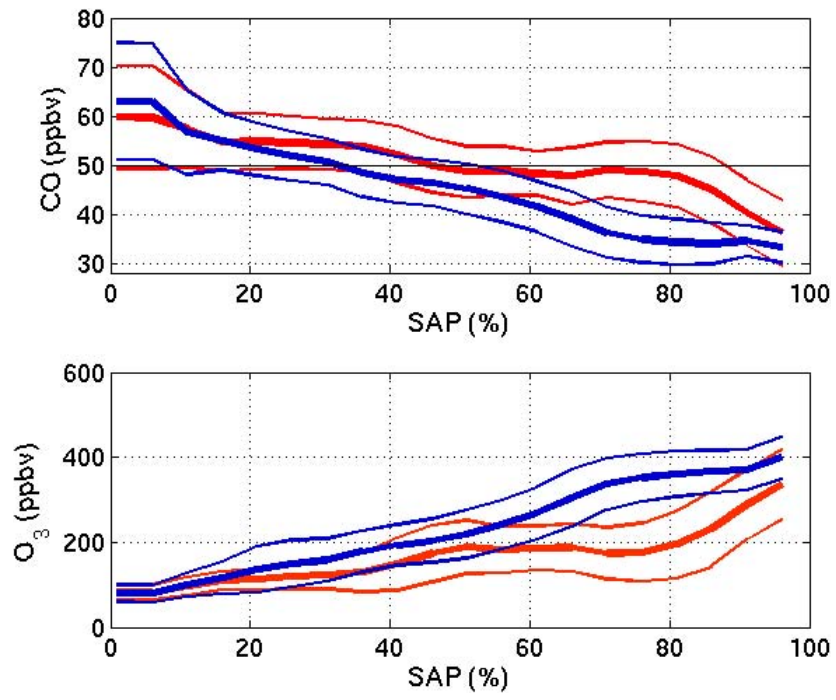

Fig. 8. Same as Fig. 6 but for parcels belonging to the tropics

rier effect of winter subtropical jet (Haynes and Shuckburgh, 2000b). Closer to the equator, the distribution broadens in the troposphere and extends to the ground. This feature emphasizes the contribution of tropical convection to the chemical composition of the extratropical "overworld" suggested by Dessler and Sherwood (2004). It shows that, even in northern winter, a part of the subtropical parcels initialised above $360 \mathrm{~K}$ are found to originate from the tropical boundary layer after being lifted up to about $350 \mathrm{~K}$ by convective transport. Interestingly, no tropospheric sources are found at higher latitudes than $30 \mathrm{~N}$. This discards the hypothesis of a subtropical or extratropical tropospheric source to explain the trace gas composition observed in this region above $350 \mathrm{~K}$. Hence, the fast and local mixing events close to the tropopause appear as limited to a shallow layer, and are not able to significantly impact the overlaying levels, even by the diffusive upward propagation over long time scale. This analysis confirms that above the tropopause layer the composition of the lower stratosphere is controlled by long term mixing between the tropical tropospheric air advected from the TTL with stratospheric air from the overworld. In agreement with in situ observations of Hoor et al. (2004) in the extratropics, and Lagrangian calculations of Berthet et al. (2007), the TTL is shown to act as a tropospheric reservoir for the lower stratosphere at higher latitude. The wide range of latitudes found for parcel origins within the TTL establishes the importance of the meridional exchanges for the subtropical lower stratosphere, a feature that significantly differs from the stronger role of atmospheric descent from the overworld at higher latitudes (Appenzeller et al., 1996). 

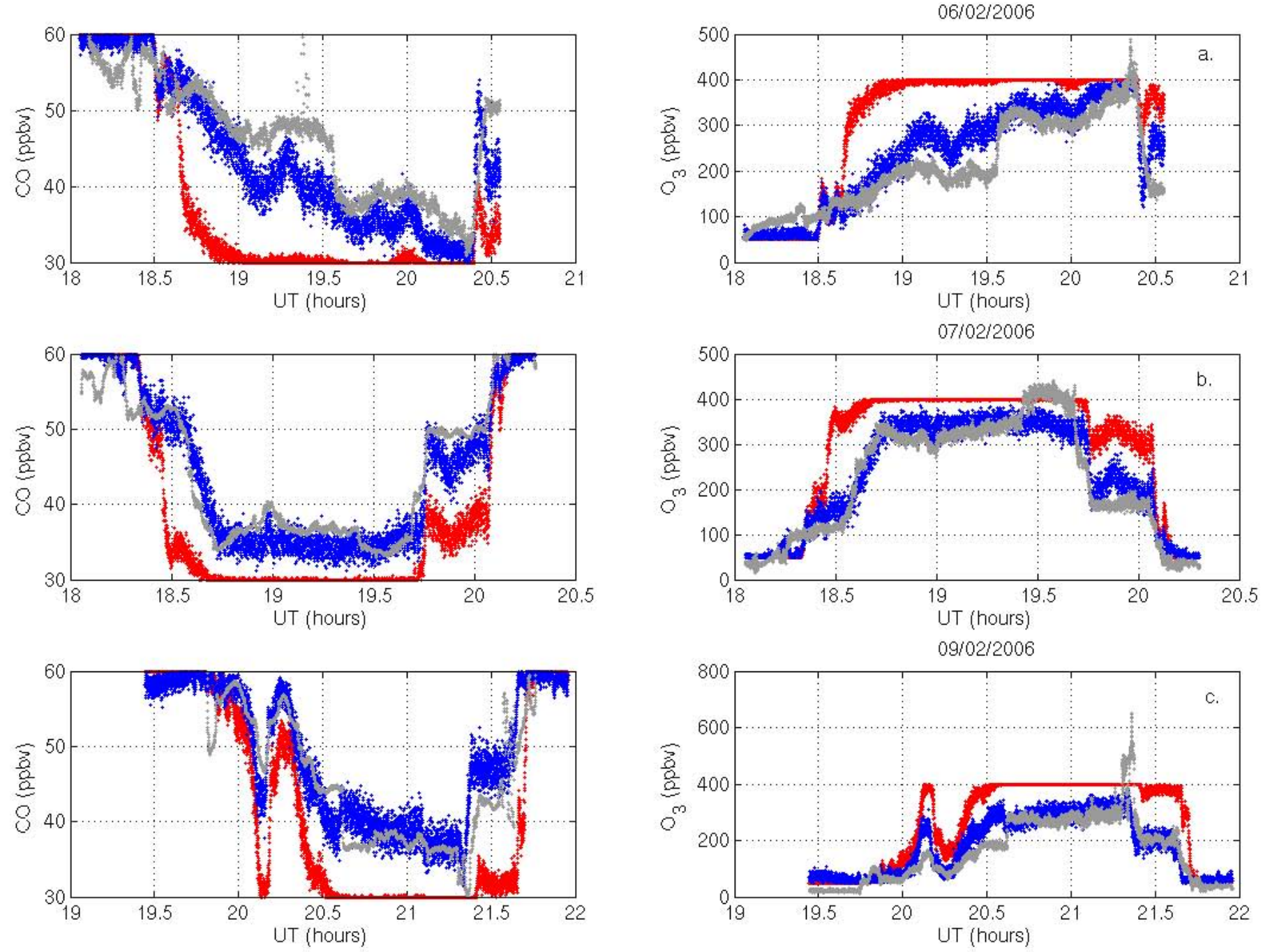

Fig. 9. Comparison between in situ measurements (grey) and reconstructed profiles from SAP calculated after 9 days (red) and 35 days (blue) for three tropical flights: a. 06/02/06; b. 07/02/06; c. 09/02/06

\section{Mixing time-scale at the tropical tropopause}

6.1 Long term stratospheric mixing at the tropical
tropopause

We now discuss the relation between SAP and tracers in the tropics in the layer between 340 and $450 \mathrm{~K}$. Following the same approach as in Sect. 5, $\mathrm{CO}$ and $\mathrm{O}_{3}$ are represented as a function of the SAP in Fig. 8.

Similarly to the distribution observed in Fig. 6, the tropical tracer measurements do not exhibit organised relations with the stratospheric air proportion issued from short time calculations. Indeed, for most values, the SAP do not distinguish $\mathrm{CO}$ or $\mathrm{O}_{3}$ mixing ratios when an integration time of 9 days is used. For instance, a concentration of $50 \mathrm{ppbv}$ in $\mathrm{CO}$ corre- sponds to SAP values ranging from a purely tropospheric to an almost purely stratospheric composition (90\%), highlighting that the relation between the tracers and the SAP values is very weak for this time.

In the opposite, the back-trajectories retrieve quasi-linear and bijective relations with in situ tracer measurements when the SAP is calculated over 35 days. Here, the large dispersion of the $\mathrm{CO}$ concentrations found for the parcels close to a pure tropospheric proportion is an effect of the heterogeneity of tropospheric sources for $\mathrm{CO}$. Indeed, a very weak dispersion is found in the identical range of SAP values when ozone measurements are considered.

However, it is important to assess whether the dispersion of points within the lower panels of Fig. 8 is due to the variability among the 11 flights or whether the dispersion oc- 


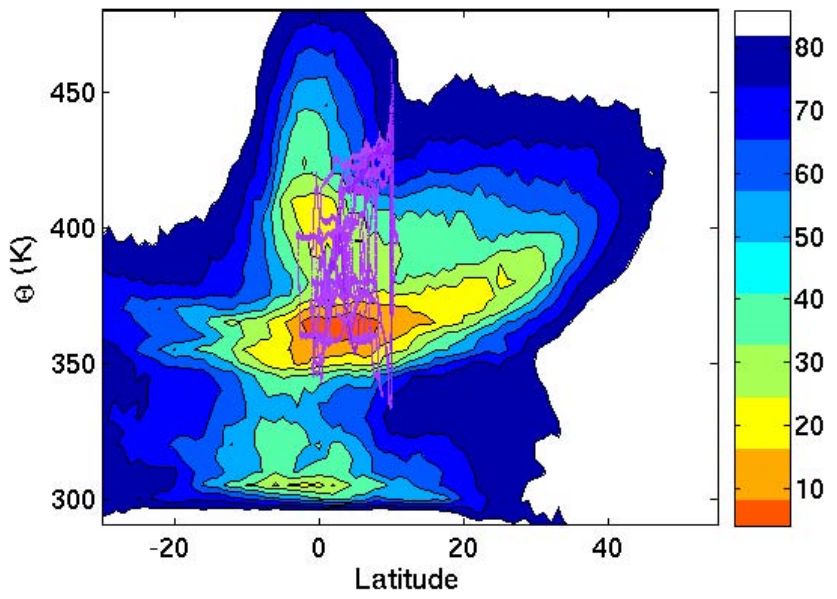

Fig. 10. Same as Fig. 4 but for the distribution of the tropical particles after an integration of one month

curs within each flight. This is equivalent to test the ability of SAP to reconstruct tracer transect during each flight. For each tracer $\chi$, the SAP is used to predict the value $\chi(t)$ along the flight track as

$$
\chi=(1-\mathrm{SAP}) * \chi^{T}+\mathrm{SAP} * \chi^{S}
$$

where $\chi^{T}$ and $\chi^{S}$ are respectively pure tropospheric and pure stratospheric values of the tracer, chosen as $\mathrm{CO}^{T}=60 \mathrm{ppbv}$, $\mathrm{CO}^{S}=30 \mathrm{ppbv}, O_{3}^{T}=100 \mathrm{ppbv}$ and $O_{3}^{S}=400 \mathrm{ppbv}$ corresponding to observed values at, respectively $360 \mathrm{~K}$ and $430 \mathrm{~K}$. Figure 9 shows three selected flights from CR-AVE, demonstrating that the reconstructions are able to reproduce most of the variations observed along the flight track after 35 days but fails dramatically after only 9 days. An average mean standard error of $7 \%$ is found for the reconstructed $\mathrm{CO}$ profiles and $15 \%$ for $\mathrm{O}_{3}$ profiles when 35-day back-trajectories are considered. This, with the fairly compact relations obtained for the mean distribution over 11 flights and two different winters strongly suggests that the distribution of long-lived tracers can be explained by the properties of transport as resolved by meteorological analysis and a simple representation of subgrid-scale effects as a diffusion.

\subsection{Slow ascent in the tropics}

In order to investigate the pathways followed by the crosstropopause transport in the tropics, Fig. 10 shows the distribution of the tropical parcels after an integration of 35 days.

Interestingly, the pattern observed seems to indicate that both vertical and meridional mixing across the tropopause are efficient in the tropical UT/LS. The two cores of the distribution found around $360 \mathrm{~K}$ and $400 \mathrm{~K}$, below and above the tropopause, respectively, are associated with an initial bimodality in the flight levels. However, it is significant that this upper maximum does not expand in latitude over 35 days while the lower core extends to $20 \mathrm{~N}$. The third core of the distribution found near the ground marks the role of convective transport from the boundary layer.

At extratropical latitudes, a large hemispheric asymmetry is found in the distribution of the particles. Poleward of $10 \mathrm{~N}$, an important contribution of the winter subtropics is found between $380 \mathrm{~K}$ and $430 \mathrm{~K}$ whereas a strong meridional gradient at $10 \mathrm{~S}$ marks the isolation of the tropics from the Southern Hemisphere above $380 \mathrm{~K}$. Actually, the upward slope on the northern flank of the distribution in the TTL suggests an influence of the winter subtropical jet in the entrainment of subtropical air in the tropics. In the Northern Hemisphere, isentropic exchanges poleward of $30 \mathrm{~N}$ are not allowed below $360 \mathrm{~K}$, while above $380 \mathrm{~K}$ subtropical air is transported into the tropics from the winter hemisphere as far as $40 \mathrm{~N}$. This result is in agreement with the existence of a mixing layer above the subtropical jet that entrains subtropical air and dumps isentropic transport in the core of the jet (Konopka et al., 2007).

However, a much smaller proportion of particles originates from the subtropics at higher altitudes above $430 \mathrm{~K}$. This inhibition of meridional exchanges in the tropical ascent is a clear signature of the tropical pipe. From Fig. 10, the isolation of the tropics is found for levels located at least a couple kilometers above the tropopause, and not directly above it. This result is in agreement with previous in situ and model studies (Rosenlof and McCormick, 1997; Neu and Plumb, 1999). The region located between the entry in the TTL and the bottom of the tropical pipe is seen as driven by mixing processes coupling the vertical ascent in the tropics to the entrainment of subtropical air by irreversible meridional exchanges between $380 \mathrm{~K}$ and $430 \mathrm{~K}$. The air newly entered in the TTL is progressively mixed within the stratosphere, leading to the slow modification of the trace gas composition along the tropical ascent.

Hence, poleward transport of tropical air in the subtropical LS (Sect. 5) and equatorward transport of subtropical air in the tropical ascent have been identified in the layer extending from the top of the winter subtropical jet to the isentrope $430 \mathrm{~K}$. The existence of this two-way exchange layer is in agreement with the general understanding of the meridional transport in the region and offers a clarification of the structure of the exchanges between the the subtropical LS and the tropical UT/LS. Focusing on measurements performed during two boreal winters, we have shown that the entrainment of stratospheric air in the tropical band exhibits a strong seasonal pattern, suggesting the existence of an annual cycle of the hemisphere involved. Indeed, large contribution are found above the winter subtropical jet whereas they are almost absent above the summer subtropical jet. 


\subsection{Age of air}

Figure 11a shows the mean vertical velocity of particles during their residence in the band between $10 \mathrm{~S}-30 \mathrm{~N}$ as a function of altitude. The values between $360 \mathrm{~K}$ and $370 \mathrm{~K}$ lay in the range 1 to $2.5 \mathrm{~mm} . \mathrm{s}^{-1}$ which is consistent with the estimate of Park et al. (2007). However, above this level and up to $460 \mathrm{~K}$, vertical velocities are smaller than $1 \mathrm{~mm}$. $\mathrm{s}^{-1}$. This result is also consistent with diabatic calculations of Randel et al. (2007) who have estimated a velocity of $0.6 \mathrm{~mm} . \mathrm{s}^{-1}$ at $17.5 \mathrm{~km}$ during winter, and shows that the vertical velocity is not homogeneous in the tropical band. The location of the vertical velocity minima is also consistent with Randel et al. (2007)

Figure $11 \mathrm{~b}$ shows the $\mathrm{CO}_{2}$-age as a function of potential temperature. This figure mirrors the distribution of reduced $\mathrm{CO}_{2}$ in the vertical and exhibits a quasi-linear profile above $360 \mathrm{~K}$ in agreement with Park et al. (2007). These authors found that recent injections by convection explains the variability of $\mathrm{CO}_{2}$ below $360 \mathrm{~K}$ while, above this level, mixing and slow ascent in the TTL generates a compact relation with the potential temperature. We found, however, that using $370 \mathrm{~K}$ instead of $360 \mathrm{~K}$ as a reference level provides a more compact relation, thus we use the isentrope $370 \mathrm{~K}$ in the following to determine the mean age of air. Horizontal segments that departs from the main branch are due to contrail sampling.

Figure 11c shows the distribution of the age of air from trajectory calculations as a function of reduced $\mathrm{CO}_{2}$. The age is truncated at 35 days by the length of the trajectories but nevertheless exhibits a linear relation over the range 5 to 30 days with a slope of $43 \mathrm{ppbv}$ per day. This is slightly larger but consistent with the observed tendency of $\mathrm{CO}_{2}$ of 30 ppbv per day.

The last panel of Fig. 11 shows the age of air determined from the trajectories as a function of the $\mathrm{CO}_{2}$-age. Although there is a significant dispersion, the mean relation is close to the median up to 25 days indicating a good agreement between the two estimates of the age of air. This indicates that the distribution of vertical motion determined from trajectory calculations is in agreement with $\mathrm{CO}_{2}$ observations.

\section{Conclusions}

We have used a Lagrangian model of diffusive backtrajectories to quantify the impact of TroposphereSratosphere mixing in airborne tracer observations. This model has been applied to aircraft measurements in the tropics and the subtropics at different altitudes during the Pre-AVE and CR-AVE campaigns. The main result shown by the calculation of the spectrum of origins of air parcels is that $\mathrm{CO}$ and $\mathrm{O}_{3}$ mixing ratio can be successfully explained by the proportion of stratospheric and tropospheric air estimated from our model with analysed winds.
In the subtropics, we have analysed a mixing line observed below $350 \mathrm{~K}$ and shown that it resulted from crosstropopause mixing generated by an active frontogenesis event on the time scale of one week. The description of this cross-tropopause pathway is in agreement with previous results on the characterization of irreversible TS exchange close to the subtropical tropopause (Wernli and Bourqui, 2002; Pan et al., 2006). In particular, back-trajectories have retrieved the tropospheric and the stratospheric sources involved in the mixing event, showing that the two initial air masses were meridionally separated by more than $1500 \mathrm{~km}$ and had two distinct chemical compositions. Such exchange processes are favored near the jet stream where isentropic surfaces intersect the tropopause, but are most certainly active locally along jet streaks at higher latitude, where similar tracer-tracer relationships are observed (Hoor et al., 2002; Pan et al., 2004).

Above $350 \mathrm{~K}$, the localisation of the tropospheric source confirms that the transport of tropical air across the tropopause above the subtropical jet is the main pathway involved in the TS irreversible exchanges in the subtropics at this altitude. Notice that we cannot distinguish whether the transport is quasi-isentropic and direct across the subtropical tropopause or occurs by rising first across the topical tropical tropopause, followed by horizontal mixing and descent. However, from the analysis of the stratospheric air proportion, we have determined a time-scale of one month for such cross-tropopause mixing. This agrees with the lower estimates found in the previous in situ (Rosenlof and McCormick, 1997; Hoor et al., 2005) and model studies (Andrews et al., 2001). The overall description provided is consistent with the existence of a mixing layer above the subtropical jet as identified by Konopka et al. (2007).

In the tropics, below $360 \mathrm{~K}$, the Lagrangian analysis retrieves a purely tropospheric origins of the measurements, which is consistent with the large $\mathrm{CO}$ variability observed and with the impact of the convection identified by Park et al. (2007). Above $360 \mathrm{~K}$ the vertical distribution and individual profiles of $\mathrm{CO}$ and $\mathrm{O}_{3}$ are determined within a range of $10 \%$ by slow mixing between tropospheric and stratospheric air over a period of a month. Indeed, the Lagrangian analysis has shown that the tropical tropospheric air newly entered in the stratosphere is mixed within the tropical ascent to achieve a fully stratospheric composition above $450 \mathrm{~K}$. In particular, the large asymmetry observed in the distribution of the stratospheric parcels points to the role of the winter subtropical jet to generate two-way meridional exchanges between $360 \mathrm{~K}$ and $450 \mathrm{~K}$.

In their study, Park et al. (2007) conclude that the vertical profile of $\mathrm{CO}_{2}$ is insensitive to diffusion by fitting a purely advective law to a quasi-linear profile, excluding de facto any influence of diffusion. If, however, the vertical velocity is not left as a free parameter but is made consistent with mass conservation and heating rates, then an equally good fit to the observations can be obtained with some finite diffusion. 

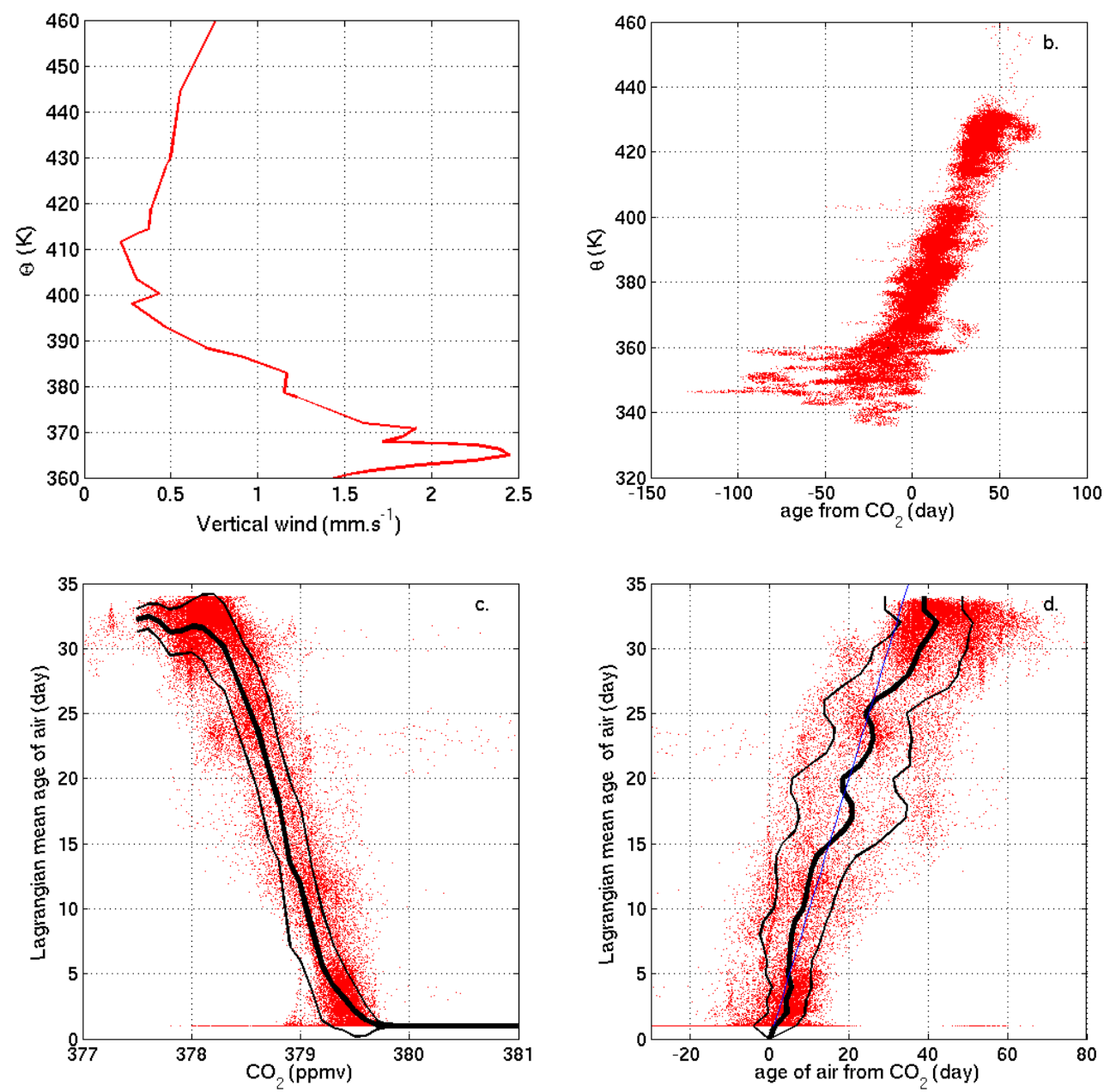

Fig. 11. (a) Average vertical velocity experienced by the particles in the tropical band (10 S and $30 \mathrm{~N})$. (b) Vertical distribution of age of air calculated from $\mathrm{CO}_{2}$ and with the reference level at $370 \mathrm{~K}$, (c) Lagrangian calculated age from trajectories and with a reference level at $370 \mathrm{~K}$ as a function of measured $\mathrm{CO}_{2}$. (d) Comparison between ages calculated from back trajectories and from $\mathrm{CO}_{2}$ measurements.

Hence, our study, where the diffusion induced by fluctuations is shown to be essential in determining the vertical profiles of tracers is not contradicted by Park et al. (2007). There is, however, a source of uncertainty in using vertical velocities from operational analysis which are known to contain a significant amount of spurious noise (Legras et al., 2005). Further studies using recent reanalysis and heating rates instead of vertical velocities are required to clarify this issue.

Acknowledgements. We acknowledge M. Loewenstein, H. Y. Jost and J. R. Podolske for CO data. We acknowledge Gao and E. C. Richards for ozone data. We acknowledge S. C. Wofsy for the $\mathrm{CO}_{2}$ data. We acknowledge the Pre-AVE and CR-AVE team and all the NASA crew for dedicated efforts. We acknowledge the support of the European Commission Integrated Project SCOUT-O3 (505390-GOCE-CT-2004).

Edited by: W. Lahoz

\section{References}

Andrews, A. E., Boering, K. A., Wofsy, S. C., Daube, B. C., Jones, D. B., Alex, S., Loewenstein, M., Podolske, J. R., and Strahan, S. E.: Empirical age spectra for the lower tropical stratosphere from in situ observations of CO2: Quantitative evidence for a sub-tropical barrier to horizontal transport, J. Geophys. Res., 106, 32 295-32 314, doi:10.1029/2001JD000465, 2001.

Appenzeller, C., Holton, J. R., and Rosenlof, K. H.: Seasonal variation of mass transport across the tropopause, J. Geophys. Res., 101, 15 071-15 078, doi:10.1029/96JD00821, 1996.

Berthet, G., Esler, G., and Haynes, P. H.: A Lagrangian perspective of the tropopause and the ventilation of the lowermost stratosphere, J. Geophys. Res., 112, D18102, doi:10.1029/ 2006JD008295, 2007.

Chen, P.: Isentropic cross-tropopause mass exchange in the extratropics, J. Geophys. Res., 100, 16661-16674, doi:10.1029/ 95JD01264, 1995.

Daube, B. C., J., Boering, K. A., Andrews, A. E., and Wofsy, 
S. C.: A High-Precision Fast-Response Airborne CO2 Analyzer for In Situ Sampling from the Surface to the Middle Stratosphere, J. Atmos. Oceanic Technol., 19, 1532-1543, doi: 10.1175/1520-0426(2002)019〈1532:AHPFRA $\rangle 2.0 . C O ; 2,2002$.

Dessler, A. E. and Sherwood, S. C.: Effect of convection on the summertime extratropical lower stratosphere, J. Geophys. Res., 109, D23 301, doi:10.1029/2004JD005209,2004, 2004.

Fischer, H., Wienhold, F. G., Hoor, P., Bujok, O., Schiller, C., Siegmund, P., Ambaum, M., Scheeren, H. A., and Lelieveld, J.: Tracer correlations in the northern high latitude lowermost stratosphere: Influence of cross-tropopause mass exchange, Geophys. Res. Lett., 27, 97-100, doi:10.1029/1999GL010879, 2000.

Grewe, V., Reithmeier, C., and Shindell, D.: Dynamic-chemical coupling of the upper troposphere and lower stratosphere region, Chemosphere, 47, 851-861, doi:10.1016/S0045-6535(02) 00038-3, 2002.

Haynes, P. H. and Shuckburgh, E.: Effective diffusivity as a diagnostic of atmospheric transport. Part I: stratosphere, J. Geophys. Res., 105, 22,777-22,794, doi:10.1029/2000JD900093, 2000a.

Haynes, P. H. and Shuckburgh, E.: Effective diffusivity as a diagnostic of atmospheric transport. Part II: troposphere and lower stratosphere, J. Geophys. Res., 105, 22,795-22,810, doi: 10.1029/2000JD900092, 2000b.

Haynes, P. H., Scinocca, J. F., and Greenslade, M. D.: Formation and maintenance of the extratropical tropopause by baroclinic eddies, Geophys. Res. Lett., 28, 4179-4182, doi:10.1029/ 2001GL013485, 2001.

Hoor, P., Fischer, H., Lange, L., Lelieveld, J., and Brunner, D.: Seasonal variations of a mixing layer in the lowermost stratosphere as identified by the CO-O3 correlation from in situ measurements, J. Geophys. Res., 107, 4044-4060, doi:10.1029/ 2000JD000289, 2002.

Hoor, P., Gurk, C., Brunner, D., Hegglin, M. I., Wernli, H., and Fischer, H.: Seasonality and extent of extratropical TST derived from in-situ CO measurements during SPURT, Atmos. Chem. Phys., 4, 1427-1442, 2004, http://www.atmos-chem-phys.net/4/1427/2004/.

Hoor, P., Fischer, H., and Lelieveld, J.: Tropical and extratropical tropospheric air in the lowermost stratosphere over Europe: A CO-based budget, Geophys. Res. Lett., 32, L13812, doi:10.1029/ 2005GL022495, 2005.

Konopka, P., Günther, G., Müller, R., dos Santos, F. H. S., Schiller, C., Ravegnani, F., Ulanovsky, A., Schlager, H., Volk, C. M., Viciani, S., Pan, L. L., McKenna, D.-S., and Riese, M.: Contribution of mixing to upward transport across the tropical tropopause layer (TTL), Atmos. Chem. Phys., 7, 3285-3308, 2007, http://www.atmos-chem-phys.net/7/3285/2007/.

Lefèvre, F., Brasseur, G. P., Folkins, I., Smith, A. K., and Simon, P.: Chemistry of the 1991-1992 stratospheric winter: Threedimensional model simulations, J. Geophys. Res., 99, 81838195, doi:10.1029/93JD03476, 1994.

Lefèvre, F., Figarol, F., Carslaw, K. S., and Peter, T.: The 1997 Arctic ozone depletion quantified from three-dimensional model simulations, Geophys. Res. Lett., 25, 2425-2428, doi:10.1029/ 98GL51812, 1998.

Legras, B., Pisso, I., Berthet, G., and Lefèvre, F.: Variability of the Lagrangian turbulent diffusion in the lower stratosphere, Atmos. Chem. Phys., 5, 1605-1622, 2005,

http://www.atmos-chem-phys.net/5/1605/2005/.
Loewenstein, M., Jost, H.-J., Grose, J., Eilers, J., Lynch, D., Jensen, S., and Marmie, J.: Argus: A new instrument for the measurement of the stratospheric dynamical tracers, $\mathrm{N} 2 \mathrm{O}$ and $\mathrm{CH} 4$, Spectrochim. Acta A, 58, 2329-2345, 2002.

Lopez, J. P., Fridlind, A. M., Jost, H.-J., Loewenstein, M., Ackerman, A. S., Campos, T. L., Weinstock, E. M., Sayres, D. S., Smith, J. B., Pittman, J. V., Hallar, A. G., Avallone, L. M., Davis, S. M., and Herman, R. L.: CO signatures in subtropical convective clouds and anvils during CRYSTAL-FACE: An analysis of convective transport and entrainment using observations and a cloud-resolving model, J. Geophys. Res., 111, D09305, doi: 10.1029/2005JD006104, 2006.

Mote, P. W., Rosenlof, K. H., M. Mclntyre, M. E., Carr, E. S., Gille, J. C., Holton, J. R., Kinnersley, J. S., Pumphrey, H. C., Russell III, J. M., and Waters, J. W.: An atmospheric tape recorder: The imprint of tropical tropopause temperatures on stratospheric water vapor, J. Geophys. Res., 101, 3989-4006, 1996.

Mullendore, G. L., Durran, D. R., and Holton, J. R.: Crosstropopause tracer transport in midlatitude convection, J. Geophys. Res., 110, D06113, doi:10.1029/2004JD0050590, 2005.

Neu, J. L. and Plumb, R. A.: Age of air in a "leaky pipe" model of stratospheric transport, J. Geophys. Res., 104, 19243-19255, doi:10.1029/1999JD900251, 1999.

Pan, L. L., Randel, W. J., Gary, B. L., Mahoney, M. J., and Hintsa, E. J.: Definition and sharness of the extratropical tropopause: A trace gas perspective, J. Geophys. Res., 109, D23103, doi:10. 1029/2004JD004982, 2004.

Pan, L. L., Konopka, P., and Browell, E. V.: Observations and model simulations of mixing near the extratropical tropopause, J. Geophys. Res., 111, D05106, doi:10.1029/2005JD006480, 2006.

Park, S., Jimenez, R., Daube, B. C., Pfister, L. T., Conway, T. J., Gottlieb, E. W., Chow, V. Y., Curran, D. J., Matross, D. M., Bright, A., Atlas, E. L., Bui, T. P., Gao, R.-S., Twohy, C. H., and C., W. S.: The CO2 tracer clock for the Tropical Tropopause Layer, Atmos. Chem. Phys., 7, 3989-4000, 2007, http://www.atmos-chem-phys.net/7/3989/2007/.

Patmore, N. and Toumi, R.: An entropy-based measure of mixing at the tropopause, Q. J. R. Meteorol. Soc., 132, 1949-1960, 2006.

Pisso, I. and Legras, B.: Turbulent vertical diffusivity in the subtropical stratosphere, Atmos. Chem. Phys., 8, 697-707, 2008, http://www.atmos-chem-phys.net/8/697/2008/.

Plumb, R. A.: Tracer-tracer relationships in the stratosphere, to appear in Rev. Geophys., http://www-eaps.mit.edu/rap, 2007.

Proffitt, M. H., Kelly, K. K., A., P. J., Gary, B. L., Loewenstein, M., Podolske, J. R., Strahan, S. E., and Chan, K. R.: Evidence for diabatic cooling and poleward transport within and around the 1987 Antarctic ozone hole, J. Geophys. Res., 94, 16 797-16813, doi:10.1029/89JD00905, 1989.

Randel, W. J., Park, M., Wu, F., and Livesey, N.: A Large Annual Cycle in Ozone above the Tropical Tropopause Linked to the Brewer Dobson Circulation, J. Atmos. Sci., 64, 4479-4488, doi: 10.1175/2007JAS2409.1, 2007.

Rosenlof, K. H. and McCormick, M. P.: Hemispheric asymmetries in water vapor and inferences about transport in the lower stratosphere, J. Geophys. Res., 102, 13 213-13 234, doi:10.1029/ 97JD00873, 1997

Shapiro, M. A.: Turbulent mixing within tropopause folds as a mechanism for the exchange of chemical constituents between the troposphere and the stratosphere, J. Atmos. Sci., 37, 
994-1004, doi:10.1175/1520-0469(1980)037〈0994:TMWTFA〉 2.0.CO;2, 1980.

Stohl, A., Forster, C., Frank, A., and Wotawa, G.: Technical note: The Lagrangian particle dispersion model FLEXPART version 6.2, Atmos. Chem. Phys., 6, 2461-2474, 2005, http://www.atmos-chem-phys.net/6/2461/2005/.

Volk, C. M., Elkins, J. W., Fahey, D. W., Salawitch, R. J. Dutton, G. S., Gilligan, J. M., Proffitt, M. H., Loewenstein, M., Podolske, J. R., Minschwaner, K., Margitan, J. J., and Chan, K. R.: Quantifying transport between the tropical and mid-latitude lower stratosphere, Science, 272, 1763-1768, 1996.

Waugh, D. W.: Seasonal variation of isentropic transport out of the tropical stratosphere, J. Geophys. Res., 101, 4007-4023, doi:10. 1029/95JD03160, 1996.
Waugh, D. W. and Hall, T. M.: Age of stratospheric air: theory, observations, and models, Rev. Geophys., 40, 1010, doi:10.1029/ 2000RG000101, 2002.

Waugh, D. W., Plumb, R. A., Elkins, J. W., Fahey, D. W., Boering, K. A., Dutton, G. S., Volk, C. M., Keim, E., Gao, R.-S., Daube, B. C., Wofsy, S. C., Lowenstein, M., Podolske, J. R., Chan, K. R., Proffitt, M. H., Kelly, K. K., Newman, P. A., and Lait, L. R.: Mixing of polar air into middle latitudes as revealed by tracertracer scatter plots, J. Geophys. Res., 102, 13 119-13 134, doi: 10.1029/96JD03715, 1997.

Wernli, H. and Bourqui, M.: A Lagrangian 1-year climatology of (deep) cross-tropopause exchange in the extratropical Northern Hemisphere, J. Geophys. Res., 107, 4021, doi:10.1029/ 2001JD000812, 2002. 